\title{
A life cycle assessment of biosolarization as a valorization pathway for tomato pomace utilization in California
}

Thomas L. Oldfield ${ }^{1}$, Yigal Achmon ${ }^{2}$, Kristy M. Perano ${ }^{3}$, Ruth M. Dahlquist-Willard ${ }^{4}$, Jean S. VanderGheynst ${ }^{5}$, James J. Stapleton ${ }^{6}$, Christopher W. Simmons ${ }^{2}$ and Nicholas M. Holden ${ }^{1}$

${ }^{1}$ UCD School of Biosystems and Food Engineering, University College Dublin, Belfield, Dublin 4, Ireland

${ }^{2}$ Department of Food Science and Technology, University of California, Davis, CA 95616, United States

${ }^{3}$ Department of Biological and Environmental Engineering, Cornell University, Ithaca, NY 14850, United States

${ }^{4}$ University of California Cooperative Extension, Fresno County, Fresno, CA 93710, United

\section{States}

${ }^{5}$ Department of Biological and Agricultural Engineering, University of California, Davis, CA 95616, United States

${ }^{6}$ Statewide Integrated Pest Management Program, University of California, Kearney

Agricultural Research and Extension Center, Parlier, CA 93648, United States

Corresponding authors. E-mail: thomas.oldfield@ucdconnect.ie

\section{Abstract}

The California tomato processing industry produced circa 388,856 t of tomato pomace in 2014. While currently used for animal feed, tomato pomace could be utilized for biosolarization. Primary Energy Demand (PED) and Global Warming Potential (GWP) equivalent emissions were calculated for two valorization pathways: (i) feed for cattle; and (ii) biosolarization. In order to make these two valorization pathways comparable three management options were analyzed whereby each part of the system was satisfied, i.e. a pest management sub-system and a cattle feed sub-system. The management options were (1) tomato pomace used for cattle feed and soil pest control using fumigant Telone II and herbicide glyphosate; (2) tomato pomace used for cattle feed and soil pest control using solarization; (3) alternative cattle feed (cottonseed, canola pellets and 
31 wheat straw) and soil pest control using biosolarization with tomato pomace. Options 2 and 3 result

32 in a reduction of GWP and PED. Among management options, the GWP ranged from 64-98 kg

$33 \mathrm{CO}_{2}$-e and 1,502-2,250 MJ for PED per $\mathrm{t}$ of pomace. The majority of impacts were beyond the

34 tomato processors' immediate control, therefore encouraging the diversion of tomato pomace to

35 biosolarization may be desirable. Total savings per annum for biosolarization could be as large as

$36 \quad 7.7 \mathrm{M} \mathrm{kg} \mathrm{CO}_{2}$-e and 203,000 GJ annually.

37

38 Keywords: Pest control, cattle feed, solarization, circular economy, bioeconomy, tomato 39 processor.

40

\section{$41 \quad 1 . \quad$ Introduction}

The extensive use of pesticides in modern agricultural systems is essential in order to 43 manage pests that transmit infectious diseases and compete for resources. Approximately $2.5 \mathrm{Mt}$

44 of pesticides are used worldwide, with over $450 \mathrm{Kt}$ used in the United States of America (USA) 45 each year (Alavanja, 2009). Until recently, Methyl bromide (MeBr) was the most widely used 46 pesticide, however in accordance with the Clean Air Act (EPA, 2016) its use has been banned due 47 to its negative effect on human health and depletion of the ozone layer (UNEP, 1992). The 48 prohibition of $\mathrm{MeBr}$ has spurred innovative new designs and formulations of pesticides by 49 manufacturers and researchers to meet the global demand for pest control in agriculture. 50 Alternative and sustainable integrated pest management strategies need to have a low 51 environmental impact, be cost effective (Lichtfouse et al., 2009), and ideally, they should only be 52 toxic to the target organisms (Ros et al., 2008). 
One alternative approach to chemical pesticides use is solarization; a hydrothermal process

54 of disinfesting soil of agricultural pests. Solarization is accomplished by covering moist soil with

55 clear plastic sheeting, leading to passive solar heating and pest inactivation through a combination

56 of physical, chemical, and biological mechanisms (Stapleton, 2000). Solarization has been shown

57 to be beneficial and practical (Boz, 2009), in particular for strawberry (Yildiz et al., 2010) and

58 legume cultivation (Linke et al., 1991), and in smaller farming operations (Stapleton et al., 2005).

59 However, there are barriers preventing its widespread use. Solarization demands strict scheduling

60 to coincide with the warmest period of the year, and it suffers from variable efficiency (Stapleton,

61 2000). The addition of a soil amendment with organic matter extends solarization to the process

62 known as biosolarization, and has been shown to enhance pest-inactivating conditions (Achmon

63 et al., 2016; Simmons et al., 2013) while contributing to the mitigation of the aforementioned

64 barriers. Biosolarization and solarization research to date has focused on the technical aspects of

65 the technology with an emphasis on comparing the pest control efficacy to conventional pesticides

66 (Boz, 2009; Achmon et al., 2016; Simmons et al., 2013). Typically, the soil amendment used in

67 biosolarization is an agricultural by-product or residue. The use of agricultural by-products and 68 residues for waste valorization processes is seen as an opportunity to displace fossil alternatives

69 (Lin et al., 2013) and falls within the mandate of the bioeconomy, whereby non-renewable 70 products are replaced with renewable alternatives.

71 One location where the adoption of biosolarization is ideal due to its climate and significant 72 agricultural industry is the state of California (CA), USA. Annually, CA produces large quantities 73 of fruit processing residues (Morning Star, 2014) and also requires soil pest management for a 74 significant area of agricultural land (Epstein., et al., 2014). Solid residues from fruit processing are 75 a promising biosolarization organic amendment because they are rich in organic compounds and 
76 have limited alternate uses (Achmon et al., 2016). Pomace consists mainly of skins, seeds and

77 residual pulp that remain after the fruit has been disrupted and pressed. Achmon et al., (2016)

78 identified that for biosolarization, tomato pomace gave the best result, while white grape pomace

79 performed less effectively and red grape pomace was far less suitable.

Research has been carried out on tomato processing in CA (Brodt et al., 2013), but did not

81 include options for the management of tomato pomace. In 2007, about 260,000 $t$ (fresh weight) of

82 tomato pomace was produced by the California tomato processing industry (Matteson et al., 2007),

83 which had increased to approximately 388,856 t (fresh weight) by 2014 (Morning Star, 2014). The

84 majority of agricultural by-products are incorporated by dairy farmers into their feed rations (Silva-

85 del-Río et al., 2010), and tomato pomace has been successfully used as a component of the ration

86 in some California dairies (Cassinerio et al., 2015). If tomato pomace were to be diverted to

87 biosolarization, an ideal location would be the San Joaquin Valley, one of CA's major eggplant

88 cultivation regions (Aguiar, 2016), and where many of the tomato processors operate. Eggplant is

89 often harvested in the summer in this region, leaving the fields fallow during the warmer months

90 that are ideal for biosolarization. This also corresponds to the tomato-processing season and thus

91 the availability of pomace. Several pesticides are typically used (CEPADPR, 2016) to control soil

92 borne pests in eggplant fields. These factors make eggplant production an ideal target for

93 alternative pest management technologies like biosolarization.

Life cycle assessment (LCA) is a technique that quantifies the potential environmental

95 impact and resource consumption of a product, system or service from cradle to grave (ISO, 2006).

96 The LCA method can be employed to assess the environmental impact of utilizing tomato pomace

97 for biosolarization. To date no LCA has been published on solarization, biosolarization, or tomato

98 pomace management; however, LCA studies have been carried out that look at the valorization of 
99 wasted food products, food residues and crop residues (San Martin et al., 2016; Gassara et al., 100 2011). The approach taken by both San Martin et al., (2016) and Gassara et al., (2011) was to 101 consider these organic materials as wastes (wasted vegetables and apple pomace, respectively) that 102 would have otherwise been sent to landfill, hence they omitted the upstream impact and only 103 considered the recovery phase. For simplicity, this study followed the same established approach.

104 Such studies considered competing valorization pathways, but did not expand the systems so that 105 value-added products produced where comparable, and all parts of the system were equally 106 satisfied.

The objective of the study was to evaluate the implications, in terms of global warming 108 impact and fossil energy consumption, of utilizing tomato pomace for biosolarization rather than 109 as a component of livestock diets in the context of soil fumigation prior to eggplant crop 110 establishment in California.

$112 \quad$ 2. Materials and methods

114 2.1. Life cycle assessment

A LCA study was carried out based on ISO 14040 standard (ISO 2006) and the four stages

116 were followed (1) goal and scope definition; (2) inventory analysis; (3) impact assessment; and (4)

117 interpretation. GaBi v.6 software (Thinkstep, 2016) was used for modelling. The Centrum voor 118 Milieuwetenschappen (CML) 2001 baseline methodology (Guinée et al., 2002) was used without 119 normalisation or weighting, and included the environmental impact global warming potential 120 (GWP, kg CO2-e) and primary energy demand (PED, MJ). 

141 (feed system).

\subsubsection{Goal and scope definition}

The goal of the study was to calculate baseline environmental data for utilizing tomato pomace as a substrate for biosolarization, from the perspective of waste management/valorization as compared to use as an animal feed ingredient.

The reason for undertaking this study was to support strategic decision-making and the audience was assumed to be the scientific community, tomato processors, regulators and farmers. Two valorization pathways for tomato pomace (Table 1) were identified for California: (i) feed for cattle (the business as usual option); and (ii) biosolarization. In order to make these two valorization pathways comparable three hypothetical management options were constructed whereby each part of the system was satisfied, i.e. a pest management sub-system and cattle feed sub-system. The management options were (1) tomato pomace used for cattle feed and soil pest control using the fumigant Telone II and herbicide glyphosate; (2) tomato pomace used for cattle feed and soil pest control using solarization; (3) alternative cattle feed (cottonseed, canola pellets and wheat straw) and soil pest control using biosolarization with tomato pomace.

\subsubsection{Option 1: Business-as-usual (BaU), tomato pomace for cattle feed and pest control with} chemical fumigant.

Option 1 represents $\mathrm{BaU}$ (Figure 1), whereby tomato pomace is transported from 19 locations (Table 2) in CA, to Tulare County, CA, where it is utilized as a cattle feed ingredient

For the pest management system, the norm is the use of chemical pesticide. Prior to pesticide application, the soil must be prepared. This includes ploughing, rolling and shaping using a tractor and associated machinery. The crop eggplant, which is common to Fresno County, CA, 
145 was chosen in order to calculate how much land is treated with pesticide per ha ${ }^{-1}$. Pest control was

146 then carried out and is achieved by using Telone C17 (a combination of 1,3-dichloropropene and

147 chloropicrin) and glyphosate. It was assumed that 1,3-dichloropropene was produced in Freeport,

148 Texas (DOW, 2008), and chloropicrin was produced in Nicklor, Long Beach, CA (US ITC, 2010).

149 The mixing of 1,3-dichloropropene and chloropicrin to produce Telone $\mathrm{C} 17$ was assumed to 150 happen in Freeport, Texas (DOW, 2008). It was assumed that glyphosate was produced in Luling, 151 Louisiana (Monsanto, 2010). Both products would then be transport via train to Fresno, CA where 152 they are applied. During pesticide application plastic sheeting is used in order to trap the substance. 153 Once used, the plastic sheeting waste is transported to landfill, which is the current norm for 154 agricultural plastics in CA.

155

2.1.1.2. Option 2: tomato pomace for cattle feed and pest control with solarization.

For Option 2 (Figure 2) tomato pomace is utilized in the cattle feed system and is transported from 19 locations (Table 2) in CA, to Tulare County, CA.

For the pest management system it was assumed that solarization was implemented. Prior 160 to solarization, the soil must be prepared. This includes ploughing, rolling and shaping using a tractor and associated machinery. As per Option 1, the crop eggplant was chosen in order to 162 calculate how much land is solarized per ha ${ }^{-1}$ (Fresno County, CA). During solarization, plastic 163 sheeting is used to achieve passive solar heating and pest inactivation in conjunction with 164 irrigation, which is carried out to keep the soil moist. Once solarization is complete, the plastic 165 sheeting waste is sent to landfill, which is the current norm in CA. 
167 2.1.1.3. Option 3: a mix of cottonseed, canola pellets and wheat straw for cattle feed and pest 168 control with biosolarization utilizing tomato pomace.

169 For Option 3 (Figure 3), for the cattle feed system, tomato pomace was replaced as a feed 170 ingredient with the most likely alternative (cottonseed, canola pellets and wheat straw) to achieve 171 the net energy of lactation, crude protein, neutral detergent fiber, and ether-extractable fat 172 requirements for cattle feed, in Tulare County, CA, in the San Joaquin Valley.

173 For the pest management system it was assumed that biosolarization was carried out, 174 whereby tomato pomace is transported from 19 locations (Table 2) in CA, to Fresno County, CA., 175 where it is utilized. The tomato pomace is spread via a tractor, after which the soil is prepared. 176 This includes ploughing, rolling and shaping using a tractor and associated machinery. The crop 177 eggplant was assumed, which is common to Fresno County, CA. During biosolarization plastic 178 sheeting is used to achieve passive solar heating and pest inactivation in conjunction with 179 irrigation, which is carried out to keep the soil moist. Once biosolarization is achieved, the waste 180 plastic sheeting is sent to landfill, which is the current norm in CA.

\subsubsection{Functional unit}

The functional unit (FU) was the management of $1 \mathrm{t}$ of tomato pomace. The reference flow

184 was the annual amount of tomato pomace produced in California in 2014 (i.e. 388,856 tresh 185 weight), which was calculated from industry tomato crop and processing capacity data (Morning 186 Star, 2014) and measured values for pomace yield and moisture content (Del Valle et al., 2006). 
The system boundary for all three options include a feed system and a pest management system in order allow for comparison (Figures 1-3). The upstream burden was excluded for the

191 feed system and the starting point of the analysis was transportation of feed from a processing 192 facility, while the downstream boundary for the feed system was curtailed before cattle production. 193 For the pest control system the downstream boundary was curtailed prior to crop establishment.

\subsubsection{Contribution and sensitivity analysis}

A contribution analysis was carried out by relevant process for each option and included:

197 fumigant production, herbicide production, transport (fumigant / tomato pomace / alternative 198 feed), spreading (pomace), ploughing, roller, list and shape, plastic sheeting production, laying of 199 plastic sheeting, irrigation, solarization, biosolarization, fumigation, herbicide application, plastic sheeting removal and transport of plastic sheeting to landfill and landfill of plastic sheeting.

A sensitivity analysis was carried out for all three options for GWP using a $+/-10 \%$ 202 adjustment of activity data and parameters. For Option 1 the changes made were: fumigant 203 production impact, herbicide production impact, transport distances (herbicide and fumigant), fuel consumed for all agricultural processes, plastic sheeting used (production and landfilled), transport of plastic sheeting waste, transport of feed (tomato pomace). For Option 2 the changes made were:

206 fuel consumed for agricultural processes (except irrigation), fuel consumed during irrigation, 207 plastic sheeting used (production and landfilled), transport of plastic sheeting waste, transport of 208 feed (tomato pomace). For Option 3 the changes made were: transport distances (tomato pomace), 209 fuel consumed for all agricultural processes (except irrigation), fuel consumed during irrigation, 210 plastic sheeting used (production and landfilled), transport of plastic sheeting waste, transport of 211 alternative feed (cottonseed, canola pellets and wheat straw). 
213 2.2. Life Cycle Inventory

214 Life cycle inventory data was gathered from observed field and laboratory data from 215 experiments carried out at the University of California, Davis in Davis, CA and at the UC Kearney 216 Agricultural Research and Extension Center in Parlier, CA. Background data was taken from 217 ecoinvent (ecoinvent, 2015), FEAT (2016), and GaBi 6 (thinkstep, 2015).

\subsubsection{Tomato pomace distribution}

The processing of tomatoes for the production of tomato paste results in a residue of $4 \%$ 221 mass as tomato pomace (77\% Moisture content, Fresh weight basis) (Del Valle et al., 2006). It

222 was assumed that tomato pomace used as cattle feed and as a substrate for biosolarization was 223 distributed wet from the processing facility. The pomace was distributed from 19 identified

224 locations (Table 2), to a dairy farm assumed to be in Tulare County, CA, or an eggplant grower in 225 Fresno County, CA. The distance from each of the 19 processing plants was calculated using the 226 shortest distance (Table 2).

227

\subsubsection{Alternative feed for cattle}

229 To find a nutritionally similar substitute for the tomato pomace in dairy rations, popular 230 dairy feedstuffs were identified through an extension survey (Silva-del-Río et al., 2010) of feeding 231 management practices on 120 California dairies. The average nutrient composition of tomato 232 pomace along with the four most popular by-products used in dairy rations (almond hulls, canola 233 pellets, flaked corn grain, and whole cottonseeds) and the four most popular forages (alfalfa hay, 234 corn silage, oat hay, and wheat straw) were evaluated using the University of California 
235 Cooperative Extension feed composition library (Beef Magazine, 2010). Linear programming was 236 used to find the optimal linear combination of the eight potential substitute feedstuffs that best 237 matched the nutrient composition of tomato pomace for net energy of lactation, crude protein, 238 neutral detergent fiber and fat by minimizing the least squared differences of the four parameters. 239 The optimized solution found was cottonseed (whole, with lint), canola pellets and wheat straw at 240 a 46:24:30 mass ratio ( $<10 \%$ water on fresh weight basis). Assumptions for production of the 241 alternate feeds were: (i) cottonseeds from San Joaquin Valley, CA (347 km) (CCCGA, 2016); (ii) 242 canola pellets from American Falls, Idaho (1421 km), (Capital Press, 2016); and (iii) wheat straw 243 from Fresno County $(62 \mathrm{~km})$ (USDA, 2015). Transportation from production location to utilization 244 as feed location was assumed to be by truck.

\subsubsection{Eggplant establishment}

247 The assumed location for eggplant establishment was Fresno County, CA, in the San 248 Joaquin Valley. Eggplant is grown in plots with a row width of $1 \mathrm{~m}$, and $1 \mathrm{~m}$ spacing $(50 \%$ land 249 utilization).

250

\subsubsection{Agricultural field operations}

252 Common processes for field operations in all pest management options included ploughing, 253 roller, list and shape, tarping and plastic sheeting removal (Table 3). It was assumed that for all 254 agricultural processes a 100-horse power (hp) tractor was used with fuel consumption estimated 255 using the Flash Environmental Assessment Tool (FEAT, 2016). The data used for modelling 256 solarization and biosolarization were obtained from field and laboratory trials performed in UC 257 Davis and supplemented with data from literature (Table 3). 


\subsubsection{Solarization}

For the solarization scenario, additional processes modelled to Section 2.2.4 were irrigation

261

262

263

264

265

266

267

268

269

270

271

272 subsequent to that bed listing would be completed. One week later the plastic sheeting is laid with

273 drip irrigation and used throughout the biosolarization process, with an associated fuel

274 consumption (Table 3). For biosolarization, pomace application was $123.8 \mathrm{t} \mathrm{ha}^{-1}$ (fresh weight).

275 Pomace is only applied to the beds $(1 \mathrm{~m})$ and not the margins $(1 \mathrm{~m})$, therefore the application rate

276 modelled was $61.9 \mathrm{tha}^{-1}$ (fresh weight). The assumed application rate results in 6,282 ha of land

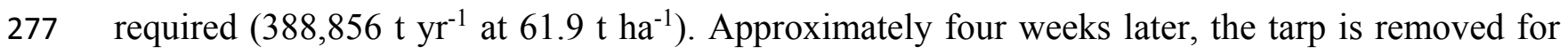

278 disposal. Biosolarization emissions are estimated to be $5.5 \mathrm{mg} \mathrm{CO} 2$ per $\mathrm{g}$ of wet pomace applied

279 based on prior work that measured emissions from soil amended with tomato pomace under the 
280

281

282

283

284

285

286

287

288

289

290

291

292

293

294

295

296

297

298

299

300

301

302

anaerobic conditions associated with biosolarization (Achmon et al., 2016), although they were not included in this study as they are biogenic (Manfredi et al., 2011).

\subsubsection{Pesticide application}

The pesticide application process was modelled. The timeline for pesticide application was ploughing, one week later levelling and three days later bed listing. After one week plastic sheeting is laid, and fumigant and herbicide application takes place. The plastic sheeting is removed and disposed of approximately 3 days later. LCI data for pesticide application included the processes fumigant and herbicide application and were taken from literature (FEAT, 2016). For each of these processes fuel consumption and associated emissions were calculated. The fumigant (Tellone II) application rate modelled was $62.51(112 \mathrm{~kg})$ per hectare, considering margins. Herbicide was modelled at a rate of $0.2 \mathrm{~kg}$ of active ingredient per hectare or 46.91 of spray solution per hectare, considering margins. Data (Table 3) for the production of fumigant was estimated (FEAT, 2016; FAO, 2015; Ecoinvent, 2016). The production impact of herbicide was taken from FEAT (2016) and averaged from four studies. Herbicide and pesticide parameters were tested in the sensitivity analysis. Fumigant and herbicide application emissions relating to GWP were assumed to be zero.

\subsubsection{Plastic sheeting production and disposal}

The plastic sheeting (polyethylene) was assumed to be produced in Point Comfort, Texas, $(2787 \mathrm{~km})$ and transported by rail. LCI data for plastic sheeting production was taken from Ecoinvent 3.1 (Ecoinvent, 2016). The disposal of plastic sheeting waste was assumed to be in landfill in the closest facility to Fresno County located in Kerman (City of Fresno, 2016) approximately $118 \mathrm{~km}$ away. Specific data for landfilling of was taken from Ecoinvent 3.1. 


\subsubsection{Energy production}

LCI data for energy (US specific, average grid mix) and fuel (diesel) were taken from the

306 GaBi 6 database (Thinkstep, 2016).

307

308

\subsubsection{Transport}

For the transport of pomace (wet), fumigant, alternative feed and waste material, a diesel

310 driven, US, semi-truck with a payload of 14-16 t was assumed, with data taken from GaBi 6 311 (Thinkstep, 2016). The transport processes were modelled to have full capacity and travel $90 \%$ on 312 interstate and $10 \%$ on rural roads. For the transport of plastic sheeting and herbicide prior to use, 313 diesel rail transportation was assumed and LCI data was taken from GaBi 6 (Thinkstep, 2016).

\section{$315 \quad 3 . \quad$ Results}

The results presented are consistent with the system defined in the study scope and include

317 analysis of environmental impact, contribution analysis and sensitivity analysis as per ISO 14040 318 (2006).

3.1. Life cycle impact assessment

\subsubsection{Analysis per environmental impact}

The option with the lowest GWP impact (64 kg CO 2 -e) per FU was Option 2 (Figure 4), 323 the use of solarization for soil pest inactivation and feed demand met by tomato pomace utilization. 324 This was followed by Option 3, biosolarization and an alternate feed of cottonseed, canola pellets 325 and wheat straw, which had a total GWP impact per functional unit of $78 \mathrm{~kg} \mathrm{CO}_{2}$-e. This was an 
326 increase of $14 \mathrm{~kg}$ of $\mathrm{CO}_{2}$-e over Option 2, per tonne of pomace. Both alternate options resulted in 327 cumulatively lower impacts than $\mathrm{BaU}$, Option 1, which had a GWP of $98 \mathrm{~kg} \mathrm{CO}$-e $(53 \%$ greater 328 than Option 2 and 26\% greater than Option 3).

For PED (Figure 4), Option 2 resulted in the lowest impact at 1,502 MJ per FU. This was followed by Option 3 at 1,727 MJ, an increase of $225 \mathrm{MJ}$ per FU. As with GWP, both alternate options (2 and 3), resulted in a cumulatively lower PED than BaU at 2,250 MJ per FU. For PED $\mathrm{BaU}$ was $50 \%$ greater than Option 2 and 30\% greater than Option 3.

There was a correlation between the results of the GWP and PED analysis per FU (Figure

4). For both GWP and PED, Option 2 resulted in the lowest impact, followed by Option 3 with $\mathrm{BaU}$, Option 1, the least favourable option. For Option 3, if biogenic carbon were included for the 336 biosolarization process, the total GWP per FU would be $84 \mathrm{~kg} \mathrm{CO}_{2}-\mathrm{e}$. This would not change the ranking for GWP, but would reduce the difference $\left(14.5 \mathrm{~kg} \mathrm{CO}_{2}\right.$-e difference rather than $20 \mathrm{~kg}$ $\mathrm{CO}_{2}$-e) between Option 1 and Option 3.

\subsubsection{Contribution analysis}

For Option 1, the most significant processes contributing to GWP (Figure 5) and PED

342 (Figure 6) were the production of fumigant (37.7\% for GWP and $25.1 \%$ for PED) and the 343 production of plastic sheeting (31.6\% for GWP and 54.4\% for PED). For Option 2, the most 344 significant processes contributing to GWP (Figure 5) and PED (Figure 6) were the production of 345 plastic sheeting (33.9\% for GWP and 57\% for PED), the transport of pomace for feed (33.8\% for 346 GWP and $22.6 \%$ for PED), and fuel consumed during irrigation $(20.2 \%$ for GWP and $12.6 \%$ for 347 PED). For Option 3, the most significant processes contributing to GWP (Figure 5) and PED 348 (Figure 6) were, production of plastic sheeting (25.8\% for GWP and 49.6\% for PED), fuel 
consumed during irrigation (15.6\% for GWP and 10.1\% for PED), transportation of alternate feed (20\% for GWP and $14.2 \%$ for PED) and distribution of pomace (23.2\% for GWP and 16.4\% for PED).

For Option 1, GWP and PED had different contribution rankings. Fumigant production made the largest contribution to GWP, approximately $6 \%$ more than plastic sheeting production, while film production made the largest contribution to PED, approximately $32 \%$ more than fumigant production. However, the contribution rankings were the same for GWP and PED for Options 2 and 3.

\subsubsection{Sensitivity analysis}

The results of the sensitivity analysis (Figure 7) showed that parameter sensitivity differed between options. For Option 1 it was seen that the amount of plastic sheeting used and fumigant consumed were the most sensitive at $+/-3.09 \%$ and $+/-3.8 \%$ respectively. For Option 2 the amount of plastic sheeting consumed was most sensitive, $+/-5.3 \%$, followed by feed transport distance, +/- 3.38\%. For Option 3 the amount of plastic sheeting consumed was most sensitive, $+/-4.55 \%$, followed by transport distance of tomato as feedstock for biosolarization, $+/-2.32 \%$, and transport distance of alternate feed, $+/-2.0 \%$.

A large amount of secondary data was used for the study but no data gaps were found whilst carrying out a completeness check. The pedigree of data was limited by its availability. Background data was taken from databases, however it was found that some processes using this data, e.g. plastic sheeting production, made a large contribution for all three options and was shown to be sensitive (Figure 7). As all three options used plastic sheeting, the reduction in impact would not change the result. Fumigant production was also shown to be sensitive, but only affected 
372 Option 1 . However, it would take a $92 \%$ reduction in its $\mathrm{CO}_{2}$-e impact to change the result, i.e. for

373 it to have a lower impact than Option 3.

374

375 4. Discussion

376 4.1. Interpretation

377 In California, the diversion of tomato pomace from its current use as cattle feed ingredient 378 to an alternative utilization as a substrate for biosolarization was shown to result in a reduction of 379 GWP and PED, by $20 \%$ and 23\%, respectively. However, Option 2 was the most favorable option 380 for both GWP and PED. This is because solarization does not require additional material inputs 381 compared to other pest management options (pomace for biosolarization and fumigant and 382 herbicide production for $\mathrm{BaU})$. These materials were responsible for a large amount of the 383 estimated impact, $37.1 \mathrm{~kg} \mathrm{CO}$-e and $667 \mathrm{MJ}$ per $\mathrm{FU}$ (fumigant and herbicide production) for 384 Option 1 and $18.18 \mathrm{~kg} \mathrm{CO}$-e and $145 \mathrm{MJ}$ per $\mathrm{FU}$ for Option 3 (transport of pomace for 385 biosolarization). This study did not incorporate the efficiency of the pest management 386 technologies. Differences in their ability to control various pests in the soil and subsequent effects 387 on crop yields could influence selection of the pest control technology. This is particularly true for 388 solarization where pest inactivation can be incomplete due to heavy reliance on the local climate 389 and weather (Stapleton, 2000). Future LCAs should consider potential variability in efficacy for 390 competing pest management strategies.

391 The focus of this case study was California. If the potential reduction shown between 392 Option 1 and Option 3 was taken for the reference flow $(388,856 \mathrm{t}$ fresh weight pomace), a 393 hypothetical total reduction of $7.7 \mathrm{M} \mathrm{kg} \mathrm{CO}$-e and 203,000 GJ could be achieved. However, it 394 should be noted that biosolarization for eggplant production alone would not consume the entirety 
395 of the seasonal pomace flow. The reference flow could be used to biosolarize 6,282 ha of land under the assumed amendment conditions; however, the most recent statistics indicate that only 397567 ha of eggplant were cultivated in 2001. As a result, additional crop targets that are equally amenable to biosolarization should be considered in future LCA studies.

\subsection{Biogenic carbon}

The results of this study did not include biogenic carbon. Its inclusion would change the

402 GWP of Option 3 to $84 \mathrm{~kg} \mathrm{CO}_{2}$-e per FU, an increase of $5.5 \mathrm{~kg} \mathrm{CO}_{2}$-e per FU. The inclusion or 403 exclusion of biogenic carbon has been discussed (Guinée et al., 2009; Levasseur et al. 2012) but 404 no agreement has been reached in the context of LCA. It can be surmised that when a study may 405 be used to stimulate the bioeconomy it is important that the study is robust (Guinée et al., 2009), 406 and not including biogenic carbon could distort the results (Levasseuret al., al 2012). Therefore,

407 presenting the results with the inclusion and exclusion of biogenic carbon and how it affects the 408 results is most appropriate. In the case of this study, biogenic carbon did not distort the results.

\subsection{The bioeconomy and waste valorization}

The bioeconomy has been valued at $\$ 1.25$ trillion in the US (Batchelor, 2012) and \$2.3

412 trillion in Europe (EC, 2010). The motivation to engage in the bioeconomy is twofold: (i) the 413 reduction of greenhouse gases; and (ii) the change from fossil-based to renewable feedstock's 414 (Teagasc, 2008). Biomass is acknowledged as a sustainable alternative to fossil sources, 415 characterized as having a low carbon footprint. As was shown in this study the use of a biomass 416 substrate, tomato pomace, for biosolarization resulted in a lower carbon impact than BaU. To fully 417 assess the whole supply chain, the use of LCA ensures that if impacts are shifted elsewhere, be 
418 that upstream or downstream, this is captured. Challenges exist to the expansion of the

419 bioeconomy, as the transformations of wastes/residues to a productive use as a substrate rely on

420 those wastes/residues being produced using fossil sources. In order to reduce this reliance,

421 synergies must be identified between and within systems. In this study the use of a crop by-product,

422 tomato pomace, to be utilized for another crop, eggplant, was shown to be environmentally 423 beneficial.

424

425 4.4. Benchmarking biosolarization in California

This baseline LCA serves as a benchmark to consider how best to reduce impacts for

427 biosolarization in CA. For this case study, the co-location of food production and processing

428 systems would further reduce carbon and energy impacts and accelerate the development of a

429 circular bioeconomy. Such approaches have been shown to be feasible and environmentally

430 sustainable in other situations such as eco-industry parks relying on industrial symbiosis. As a

431 result, considering additional biosolarization sites proximal to each tomato processing facility may

432 reveal additional impact reductions. This study assumed that plastic sheeting used during all three

433 alternatives would be sent to landfill, which is the common management approach in the tomato

434 sector in California (CIWMB, 2008). Plastic sheeting waste disposal was not found to be a hotspot,

435 but its production was important. Therefore, if closed loop plastic sheeting recycling was feasible,

436 which is in line with circular economy principles, there is the potential for a reduction in the

437 environmental impact and thus should be included in future research goals, and considered in 438 future studies of solarization/biosolarization. It was also assumed that the tomato pomace used as 439 feed would be distributed to Tulare County. If sufficient cattle were present in Fresno County for 440 consumption of the tomato pomace, a reduction of $3.52 \mathrm{~kg} \mathrm{CO}$-e and $55 \mathrm{MJ}$ per FU could 
441 potentially be saved. However this is based on an assumed average distance. In order to fully

442 exploit the potential environmental and economic saving, transport optimization would also be

443 necessary.

444

445 4.3. Future biosolarization research

446 Future LCAs of biosolarization should include additional environmental impacts such as 447 eco-toxicity potential and human-toxicity potential as these relate to pesticide use (Margni et al., 448 2002) and a water use indicator related to irrigation (Hoekstra et al., 2011). The use of a 449 downstream functional unit for valorization technologies is recommended (Oldfield et al. 2016); 450 such as pest suppression per $\mathrm{m}^{2}$ that includes an assessment of the efficiency of biosolarization 451 versus its alternatives (solarization and chemical pesticides) should be considered.

452 In order to make biosolarization more attractive as an alternative to fumigation in the 453 bioeconomy, future research should include: (i) the use of an alternative material to plastic with a 454 lower environmental impact; (ii) the optimization of water usage during irrigation, which is a 455 particular barrier for California due to water stress; and (iii) feasibility of co-location of crop and 456 processing systems. However, it was found that the majority of the impacts were shown to be 457 outside of the tomato processors' immediate control, and as such the diversion of tomato pomace 458 to biosolarization must be encouraged.

459

\section{$460 \quad 5.0 \quad$ Conclusion}

The utilization of tomato pomace for biosolarization in California, in the context of soil

462 fumigation prior to eggplant crop establishment rather than as a component of animal feed was

463 seen to be environmentally beneficial from a global warming impact and energy conservation 
464 perspective when compared to business as usual. However, solarization was found to be a better 465 option due to its reduced resource input but this LCA did not incorporate the efficiency of the 466 pest management technologies. Future LCAs of waste valorization for pest control should 467 consider using a qualitative downstream functional unit. To increase the appeal of biosolarization 468 in the circular bioeconomy, fuel consumption during irrigation and plastic sheeting use during 469 the biosolarization process need further research to identify how best to reduce their contribution 470 to environmental impact. Further environmental reductions may be possible by crop synergy co471 location. Further studies must consider water consumption, eco-toxicity potential, and human472 toxicity potential.

473

\section{Acknowledgments}

475 We would like to thank the Institute of Food and Health (UCD, Dublin) and the Irish 476 Research Council Government of Ireland funding scheme for financial support. Data collection 477 was supported by the California Department of Pesticide Regulation (grant agreement number 14478 PML-R004) and the National Science Foundation (CBET-1438694). 
480

481

482

483

484

485

486

487

488

489

490

491

492

493

494

495

496

497

498

499

\section{References}

Achmon, Y., Harrold, D.R., Claypool, J.T., Stapleton, J.J., VanderGheynst, J.S., Simmons, C.W., 2016. Assessment of tomato and wine processing solid wastes as soil amendments for biosolarization. Waste Manag. 48, 156-164. doi:10.1016/j.wasman.2015.10.022

Aguiar, 2016. Eggplant production in California. anrcatalog.ucanr.edu/pdf/7235.pdf (accessed 06.08.16).

Alavanja, M.C.R., 2009. Pesticides Use and Exposure Extensive Worldwide. Rev. Environ. Health 24, 303-309. doi:10.1515/REVEH.2009.24.4.303

Batchelor, S. New Opportunities: Renewable Chemicals and Biobased Products. http://energyoutlook2012.naseo.org/presentations/Batchelor-Renewable_Chemicals_andBiobased_Products.pdf (accessed 06.08.16).

Beef Magazine, 2010. What's the feed composition value of that cattle feed? http://beefmagazine.com/nutrition/feed-composition-tables/feed-composition-valuecattle-0301 (accessed 06.08.16).

Brodt, S., Kramer, K.J., Kendall, A., Feenstra, G., 2013. Comparing environmental impacts of regional and national-scale food supply chains: a case study of processed tomatoes. Food Policy 42, 106-114. doi:10.1016/j.foodpol.2013.07.004

California Environmental Protection Agency Department of Pesticide Regulation, 2016. Summary of Pesticide Use Report Data 2014 Indexed by Commodity. http://www.cdpr.ca.gov/docs/pur/pur14rep/comrpt14.pdf (accessed 06.08.16). 
500 California Cotton Ginners and Growers Association, 2016. Cotton facts. http://www.ccgga.org/ $501 \quad$ (accessed 06.08.16).

502 California Integrated Waste Management Board, 2008. Postconsumer Agricultural Plastic

503 Report. http://www.wastexchange.org/upload_publications/CIWMBAgPlasticsReport.pdf 504 (accessed 06.08.16).

505 Capital press, 2016. Idaho-grower-tries-new-canola-production-method.

506 http://www.capitalpress.com (accessed 06.08.16).

507 Cassinerio, C.A., Fadel, J.G., Asmus, J., Heguy, J.M., Taylor, S.J., DePeters, E.J., 2015. Tomato

508 seeds as a novel by-product feed for lactating dairy cows. J. Dairy Sci. 98, 4811-4828.

509 doi:10.3168/jds.2014-9121

510 City of Fresno, 2016. American Avenue Landfill.

511

512

513

514

Del Valle, M., Camara, M., Torija, M.E., 2006. Chemical characterization of tomato pomace. J http://www.fresno.gov/Government/DepartmentDirectory/PublicUtilities/SolidWaste/add itional/americanavelandfill.htm (accessed 06.08.16).

DOW, 2008. Product Safety Assessment -1,3-Dichloropropene. www.dow.com (accessed 516 06.08.16).

517 Ecoinvent Centre, 2016. Ecoinvent data v3. Final reports Ecoinvent 2000 (1-15). Swiss Centre 518 for Life Cycle Inventories, Duebendorf (CD-ROM). 
519 Environmental Protection Agency (USA), 2016. The Plain English Guide to the Clean Air Act;

520

521

522

523

524

525

526

527

528

529

530

531

532

533

534

535

536

537

538 https://www.epa.gov/clean-air-act-overview/plain-english-guide-clean-air-act (accessed 06.08.16).

Epstein, L., Zhang, M., 2014. The impact of integrated pest management programs on pesticide use in California, USA. Peshin, R., Pimentel, D., (Eds). Integrated pest management: Experiences with implementation, global overview, vol.4. Integr. Pest Manag. Exp. with Implementation, Glob. Overview, Vol.4 1-574. doi:10.1007/978-94-007-7802-3E Peshin, D Pimentel (Eds.), Integrated Pest Management, Springer-Verlag, Netherlands, pp. 173200.

European Commission, 2010. The Knowledge Based Bio-Economy: Achievements and Challenges. https://www.vlaanderen.be/nl/publicaties/detail/the-knowledge-based-bioeconomy-kbbe-in-europe-achievements-and-challenges (accessed 06.08.16).

Food and agriculture organization, 2015. Global database of GHG emissions related to feed crops. http://www.fao.org/fileadmin/user_upload/benchmarking/docs/leap_methodolgy_ draft.pdf (accessed 06.08.16).

Farm Energy Analysis Tool, 2016. Farm Energy Analysis Tool. http://www.ecologicalmodels.psu.edu/agroecology/feat/ (accessed 06.08.16).

Gassara, F., Brar, S.K., Pelletier, F., Verma, M., Godbout, S., Tyagi, R.D., 2011. Pomace waste management scenarios in Québec-Impact on greenhouse gas emissions. J. Hazard. Mater. 192, 1178-1185. doi:10.1016/j.jhazmat.2011.06.026 
Guinee, J.B., Gorree, M., Heijungs, R., Huppes, G., Kleijn, R., De Koning, A., Van Oers, L., Wegener Sleeswijk, A., Suh, S., Udo de Haes, H.A., De Bruijn, J.A., Van Duin, R., Huijbregts, M.A.J., 2002. Handbook on Life Cycle Assessment: Operational Guidelines. Kluwer Academic Publishers.

Guinée, J.B., Heijungs, R., Van Der Voet, E., 2009. A greenhouse gas indicator for bioenergy: Some theoretical issues with practical implications. Int. J. Life Cycle Assess. 14, 328-339. doi:10.1007/s11367-009-0080-X

Hoekstra, A.Y., Chapagain, A.K., Aldaya, M.M., Mekonnen, M.M., 2011. The Water Footprint Assessment Manual: Setting the Global Standard, Earthscan.

ISO, 2006. International Organization for Standardization. Environmental management - Life cycle assessment - Principles and framework, second ed., ISO 14040:2006.

Levasseur, A., Lesage, P., Margni, M., Samson, R., 2013. Biogenic Carbon and Temporary Storage Addressed with Dynamic Life Cycle Assessment. J. Ind. Ecol. 17, 117-128. doi:10.1111/j.1530-9290.2012.00503.x

Lichtfouse, E., Navarrete, M., Debaeke, P., Ere, V., Alberola, C., Ménassieu, J., 2009. Agronomy for sustainable agriculture. A review. Agron. Sustain. Dev 29, 1-6. doi:10.1051/agro:2008054

Lin, C.S.K., Pfaltzgraff, L.A., Herrero-Davila, L., Mubofu, E.B., Abderrahim, S., Clark, J.H., Koutinas, A., Kopsahelis, N., Stamatelatou, K., Dickson, F., Thankappan, S., Mohamed, Z., Brocklesby, R., Luque, R., 2013. Food waste as a valuable resource for the production of chemicals, materials and fuels. Current situation and global perspective. Energy Environ. Sci. 6, 426-464. doi:10.1039/C2EE23440H 
561 Linke, K.H., Saxena, M.C., Sauerborn, J., Masri, H., 1991. Effect of soil solarization on the yield 562 of food legumes and on pest control, in: De Vay, J.E., Staplelton, J.J., Elmore, C.L., (Eds.). 563 Soil solarization. Proc. 1st Intl. Conf. Soil Solarization. Amman, Jordan, 19-25. Feb. 1990. $564 \quad$ FAO Plant Prod. Protection Paper 109.

565 Manfredi, S., Tonini, D., Christensen, T.H., 2011. Environmental assessment of different 566 management options for individual waste fractions by means of life-cycle assessment modelling. Resour. Conserv. Recycl. 55, 995-1004. doi:10.1016/j.resconrec.2011.05.009

568 Margni, M., Rossier, D., Crettaz, P., Jolliet, O., 2002. Life cycle impact assessment of pesticides 569 on human health and ecosystems 93, 379-392.

570 Matteson, G.C., Jenkins, B.M., 2007. Food and processing residues in California: Resource 571 assessment and potential for power generation. Bioresour. Technol. 98, 3098-3105.

572 doi:10.1016/j.biortech.2006.10.031

573 Monsanto, 2010. Monsanto Announces Completion of Glyphosate Plant Expansion at Luling. 574 http://news.monsanto.com/press-release/monsanto-announces-completion-glyphosate575 plant-expansion-luling (accessed 06.08.16).

576 Morning Star, 2014. Tomato Paste and Processed Tomato Statistics.

577 http://morningstarco.com/statdocs/2014_Tomato_Stats.pdf (accessed 06.08.16).

578 Oldfield, T.L., White, E., Holden, N.M., 2016. An environmental analysis of options for utilising 579 wasted food and food residue. J. Env. Manage. In press 
580

581

582

583

584

585

586

587

588

589

590

591

592

593

594

595

596

597

598

Özhan Boz, 2009. Effects of olive processing waste, chicken manure and Dazomet on weeds with or without soil solarisation. African J. Biotechnol. 8, 4946-4952. doi:10.4314/AJB.V8I19.65197

Ros, M., Garcia, C., Hernandez, M.T., Lacasa, A., Fernandez, P., Pascual, J.A., 2008. Effects of biosolarization as methyl bromide alternative for Meloidogyne incognita control on quality of soil under pepper. Biol. Fertil. Soils 45, 37-44. doi:10.1007/s00374-008-0307-1

San Martin, D., Ramos, S., Zufía, J., 2016. Valorisation of food waste to produce new raw materials for animal feed. Food Chem. 198, 68-74. doi:10.1016/j.foodchem.2015.11.035

Silva-del-Río, N., Heguy, J.M., Lago, A., 2010. Feeding Management Practices on California Dairies. http://cetulare.ucanr.edu/files/74080.pdf (accessed 06.08.16).

Simmons, C.W., Guo, H., Claypool, J.T., Marshall, M.N., Perano, K.M., Stapleton, J.J., VanderGheynst, J.S., 2013. Managing compost stability and amendment to soil to enhance soil heating during soil solarization. Waste Manag. 33, 1090-1096. doi:10.1016/j.wasman.2013.01.015

Stapleton, J.J., 2000. Soil solarization in various agricultural production systems. Crop Prot. 19, 837-841. doi:10.1016/S0261-2194(00)00111-3

Stapleton, J.J., Molinar, R.H., Lynn-Patterson, K., McFeeters, S.K., Shrestha, A., 2008. Methyl bromide alternatives ... Soil solarization provides weed control for limited-resource and organic growers in warmer climates. Calif. Agric. 59, 84-89. doi:10.3733/ca.v059n02p84 
599 Teagasc, 2008. Teagasc's Role in Transforming Ireland's Agri-Food Sector and the Wider Bioeconomy; www.teagasc.ie/publications/2008/285/ForesightReportVol1.pdf http://cetulare.ucanr.edu/files/74080.pdf (accessed 06.08.16).

602

ThinkStep, 2015. GaBi Software, version 6.2; ThinkStep: Leinfelden-Echterdingen, Germany

603 United Nations Environmental programme (1992). Synthesis report of the methyl bromide 604 interim scientific assessment and methyl bromide interim technology and economic 605 assessment, in Montreal Protocol Assess, Suppl June 1992, UNEP, Nairobi, Kenya, p 33.

606 607 608 609 610 611 612 613 614 615 616 617
United States Department of Agriculture, 2015. Quick Stats; https://quickstats.nass.usda.gov/\#745F990B-6F5D-3578-974B-0BB844A37687 (accessed 06.08.16).

United States Department of Agriculture, 2015. Other spring wheat 2014 - Yield per harvested acre by county for selected states. On-line at http://www.nass.usda.gov/ (accessed 06.08.16).

U.S. International Trade Commission, 2010. Chloropicrin from China; https://www.usitc.gov/publications/701_731/pub4142.pdf (accessed 06.08.16).

Yildiz, A., Benlioğlu, S., Boz, Ö., Benlioğlu, K., 2010. Use of different plastics for soil solarization in strawberry growth and time-temperature relationships for the control of Macrophomina phaseolina and weeds. Phytoparasitica 38, 463-473. doi:10.1007/s 12600010-0123-7 
618 Table 1 Physiochemical characteristics of Tomato Pomace, Cottonseed (whole, with lint), 619 Canola Pellets and Wheat Straw (given as \% dry weight except where noted); (Beef Magazine, 620 2010).

\begin{tabular}{lcccc}
\hline Constituent & Tomato Pomace & Cottonseed & Canola Pellets & Wheat Straw \\
\hline Fat & 10.6 & 19.4 & 2 & 1.8 \\
Protein & 23 & 23 & 41 & 3 \\
Carbohydrate & 3.78 & - & - & 57 \\
Fibre & 50 & 37 & 19 & 8 \\
Ash & 6 & 5 & 8 & 9 \\
Water* & 77 & 9 & 10 & 0.48 \\
Nitrogen & 3.68 & 3.68 & 6.56 & 0.06 \\
Phosphorus & 0.59 & 0.64 & 1.14 & 1.3 \\
Potassium & 3.6 & 1 & 1.1 & - \\
Carbon (total) & 55.3 & - & - & \\
\hline
\end{tabular}


635 Table 2 Locations of tomato processing centres in California.

\begin{tabular}{|c|c|c|c|c|}
\hline Location & $\begin{array}{c}\text { Pomace } \\
\text { production (metric } \\
\text { tonnes, fresh } \\
\text { weight) } \\
\end{array}$ & $\begin{array}{c}\text { Pomace } \\
\text { production (metric } \\
\text { tonnes, dry weight) }\end{array}$ & $\begin{array}{c}\text { Distance to Fresno } \\
\text { (horticulture) } \\
(\mathbf{k m})\end{array}$ & $\begin{array}{l}\text { Distance to } \\
\text { Tulare } \\
\text { (feed) }(\mathbf{k m})\end{array}$ \\
\hline Santa Nella & 50,808 & 11,686 & 408 & 476 \\
\hline Williams & 43,245 & 9,946 & 370 & 438 \\
\hline Los Banos & 38,164 & 8,778 & 117 & 185 \\
\hline Huron & 29,561 & 6,799 & 85.8 & 72.5 \\
\hline Lemoore & 25,866 & 5,949 & 54.1 & 49.4 \\
\hline Los Banos & 23,672 & 5,445 & 117 & 185 \\
\hline Bakersfield & 23,383 & 5,378 & 176 & 103 \\
\hline Corcoran & 19,226 & 4,422 & 81 & 29.6 \\
\hline Los Banos & 18,995 & 4,369 & 117 & 185 \\
\hline Dixon & 17,436 & 4,010 & 310 & 363 \\
\hline Woodland & 17,090 & 3,931 & 307 & 375 \\
\hline Firebaugh & 14,434 & 3,320 & 69.1 & 137 \\
\hline Williams & 14,376 & 3,307 & 370 & 438 \\
\hline Oakdale & 11,894 & 2,736 & 165 & 232 \\
\hline Helm & 11,894 & 2,736 & 47.5 & 90.1 \\
\hline Stockton & 9,873 & 2,271 & 205 & 273 \\
\hline Stockton & 9,527 & 2,191 & 205 & 273 \\
\hline Hanford & 5,081 & 1,169 & 53.7 & 36.6 \\
\hline Modesto & 4,330 & 996 & 156 & 224 \\
\hline Total & 388,856 & 89,437 & - & - \\
\hline Average & - & & 179.7 & 219.2 \\
\hline
\end{tabular}


636 Table 3 Life cycle inventory for agricultural operations (per hectare).

\begin{tabular}{|c|c|c|c|}
\hline & Option 1 & Option 2 & Option 3 \\
\hline Pomace applied (kg)* & - & - & 61,900 \\
\hline Fumigant applied (kg) & 112 & - & - \\
\hline Herbicide applied (kg active ingredient) & 0.2 & - & - \\
\hline Plastic sheeting consumed (t) & 1 & 0.7 & 0.7 \\
\hline \multicolumn{4}{|l|}{ Fuel consumed $(L)$} \\
\hline Spreading & - & - & 30.2 \\
\hline Plough & 25.3 & 25.3 & 25.3 \\
\hline Level & 29.9 & 29.9 & 29.9 \\
\hline Plastic sheeting laying & 15.15 & 15.15 & 15.15 \\
\hline Irrigation & - & 201.65 & 201.65 \\
\hline Plastic sheeting removal & 15.15 & 15.15 & 15.15 \\
\hline Emissions during soil inactivation $(\mathrm{kg} \mathrm{CO})$ & - & Negligible & 340.5 (biotic) \\
\hline Plastic sheeting disposal (t) & 1 & 0.7 & 0.7 \\
\hline
\end{tabular}




\section{Option $1(\mathrm{BaU})$}

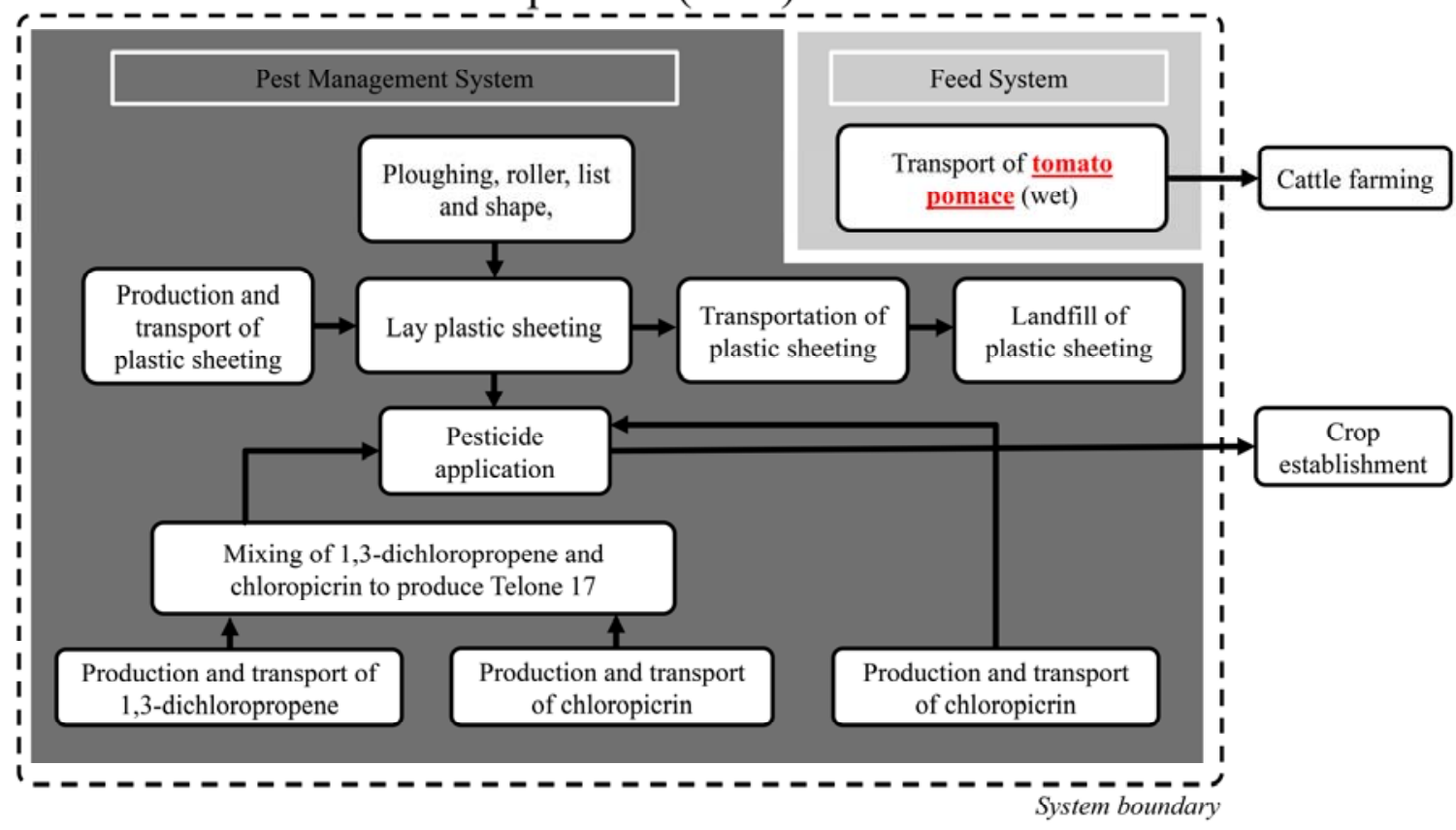

Fig. 1. System diagram and boundary for Option 1. 
Option 2

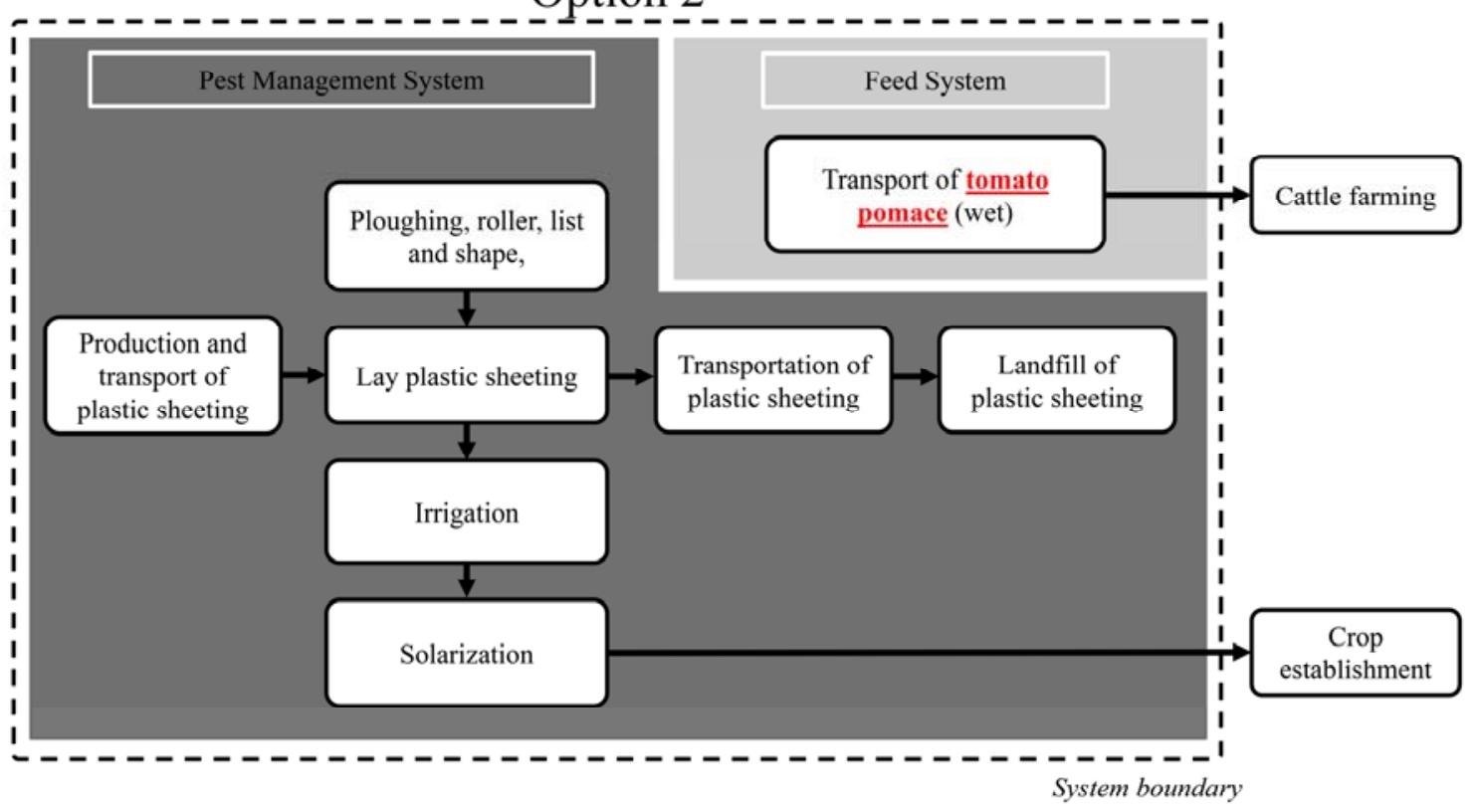

Fig. 2. System diagram and boundary for Option 2. 
Option 3

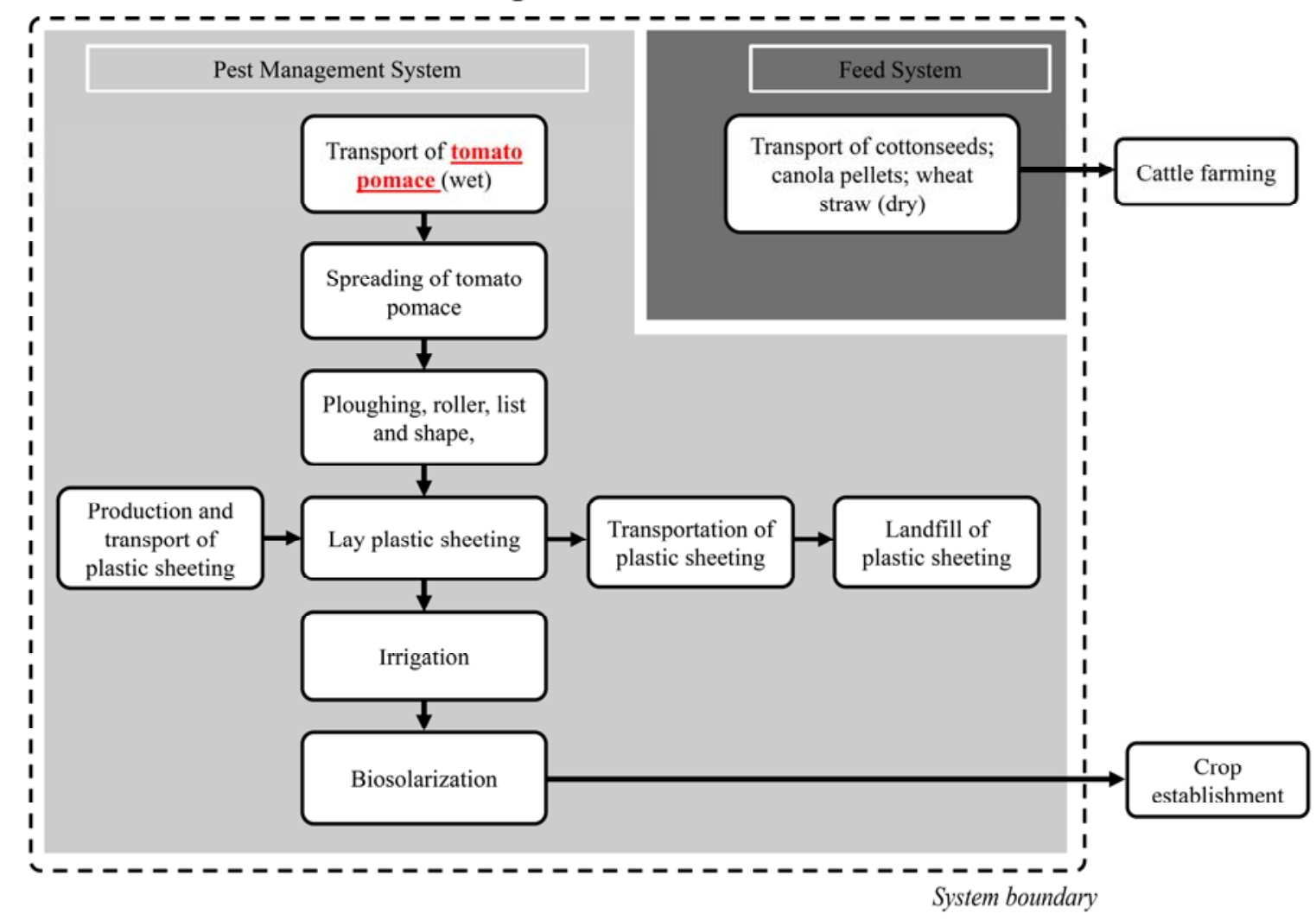

Fig. 3. System diagram and boundary for Option 3. 
648
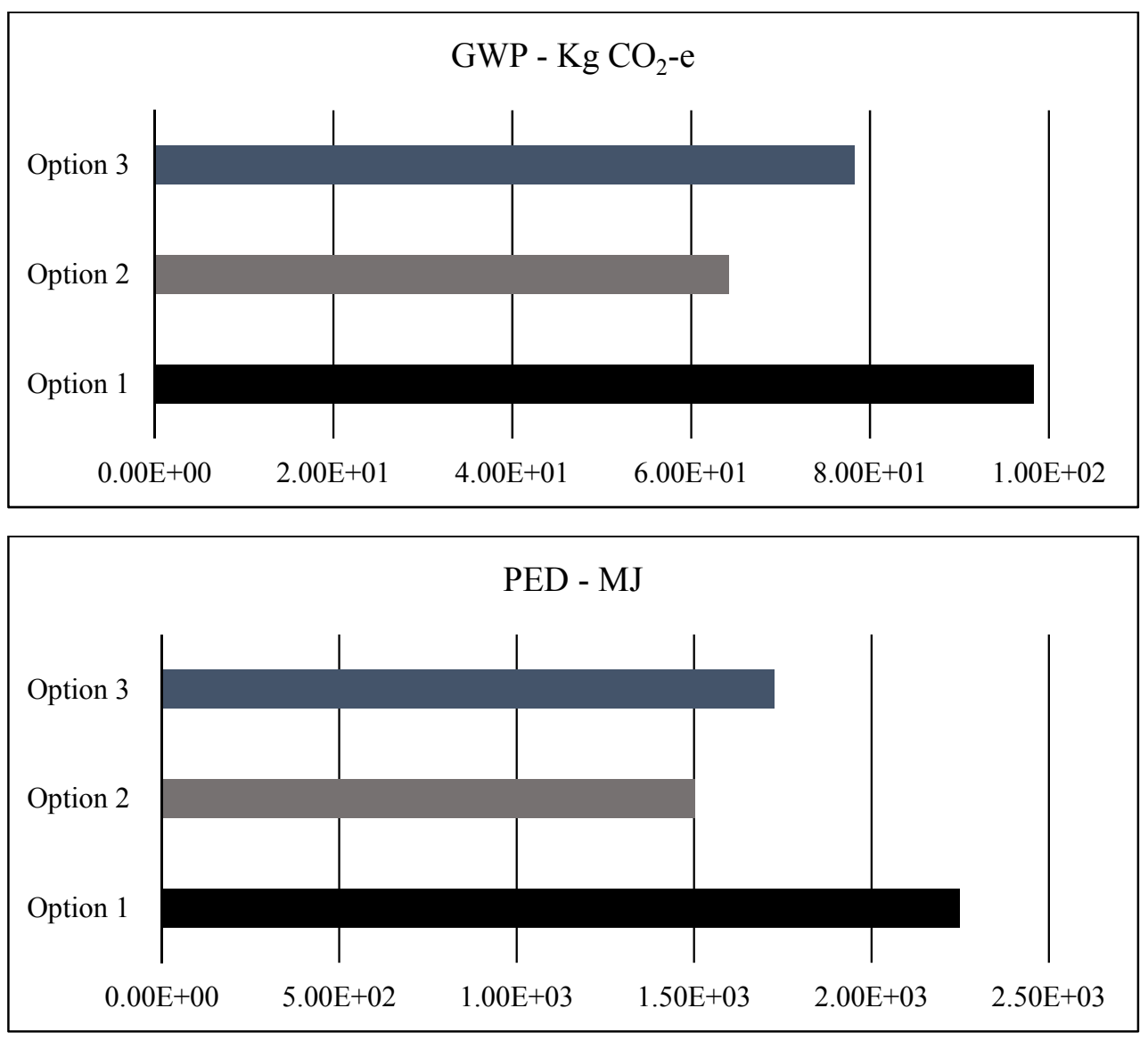

Fig. 4. Total impact for options 1-3 for global warming potential (GWP) and primary energy demand (PED). 


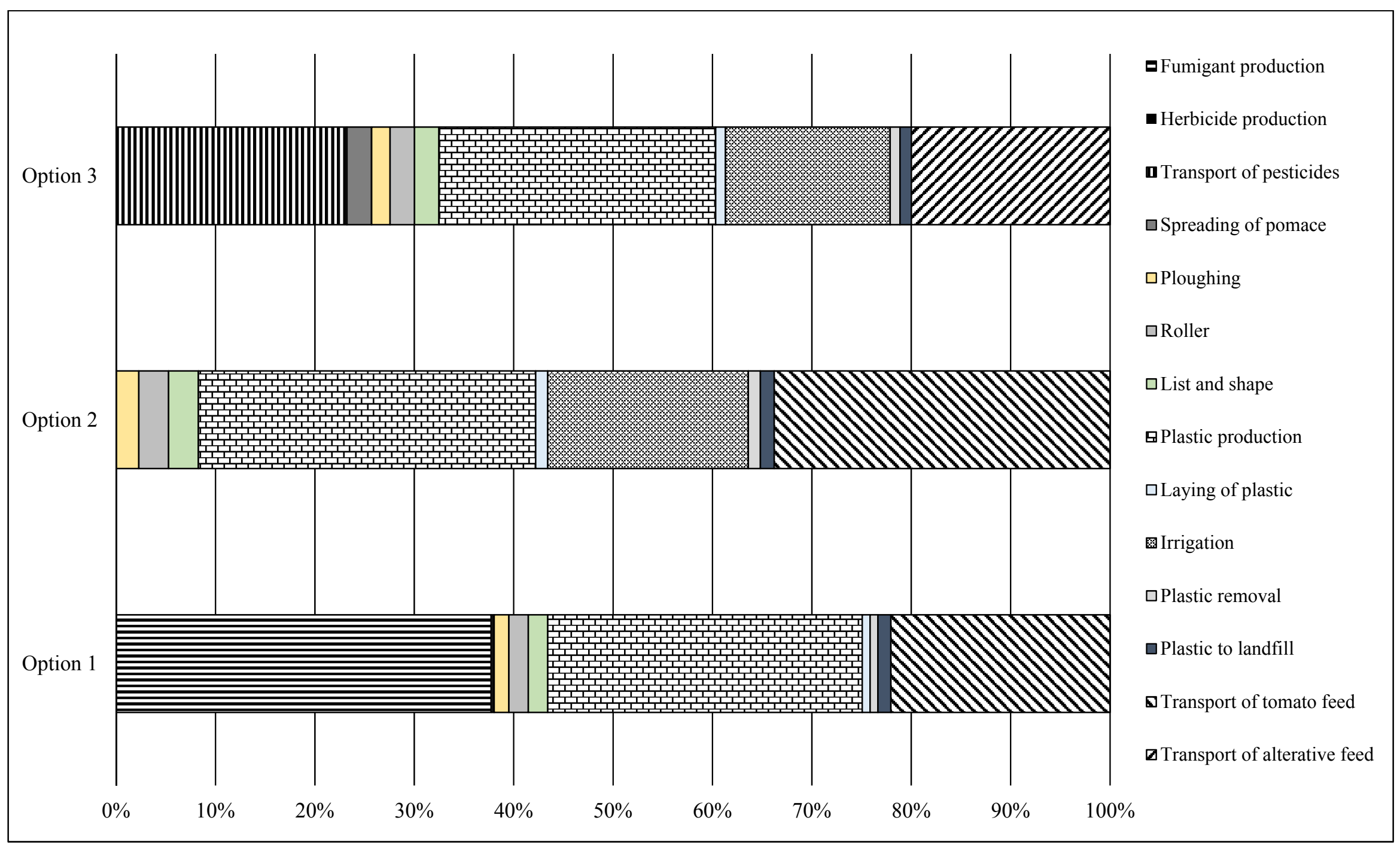

Fig. 5. Contribution analysis for option 1-3 for global warming potential $\left(\mathrm{kg} \mathrm{CO}_{2}-\mathrm{e}\right)$. 


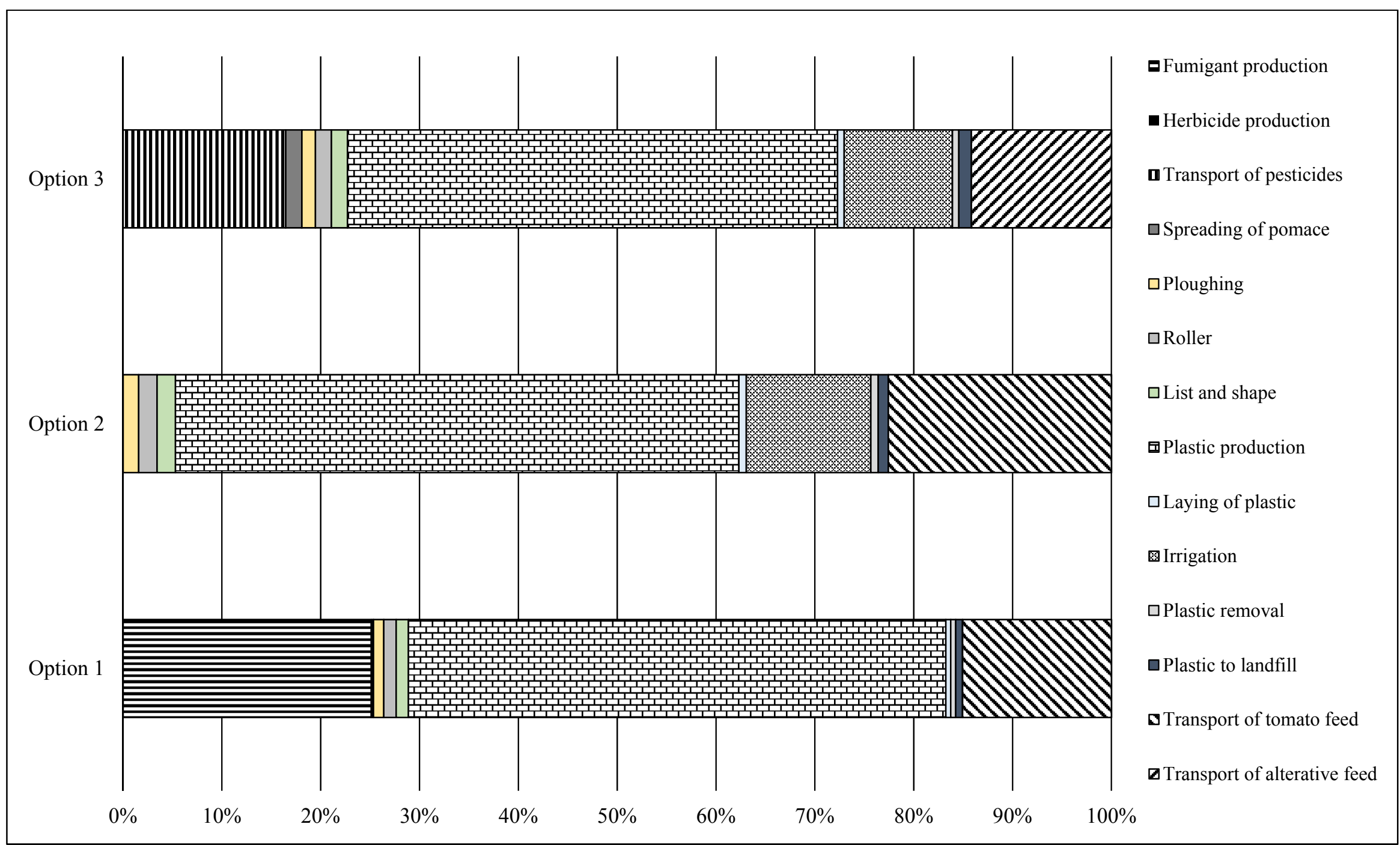

Fig. 6. Contribution analysis for options 1-3 for primary energy demand (MJ) 


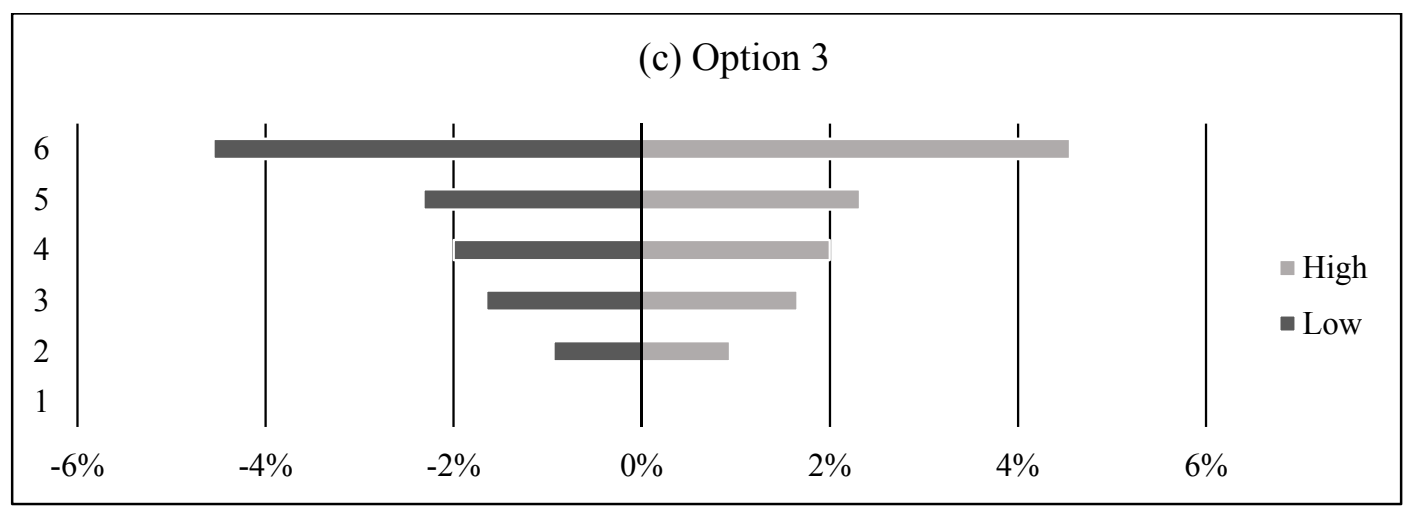

(1) Transport of waste (plastic sheeting), (2) Fuel consumed for all agricultural processes (except irrigation), (3) Fuel consumed during irrigation, (4) Transport of feed (alternative), (5) Transport distances (tomato pomace), and (6) Plastic sheeting used (production and landfilled).

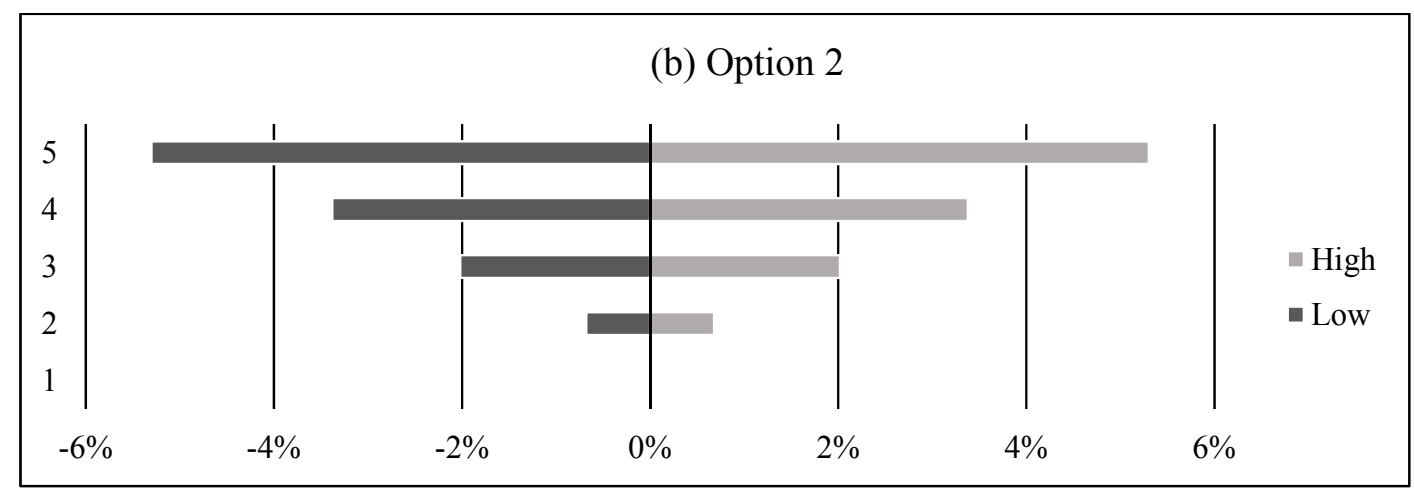

(1) Transport of waste (plastic sheeting), (2) Fuel consumed for agricultural processes (except irrigation), (3) Fuel consumed during irrigation, (4) Transport of feed (tomato pomace), and (5) Plastic sheeting used (production and landfilled).

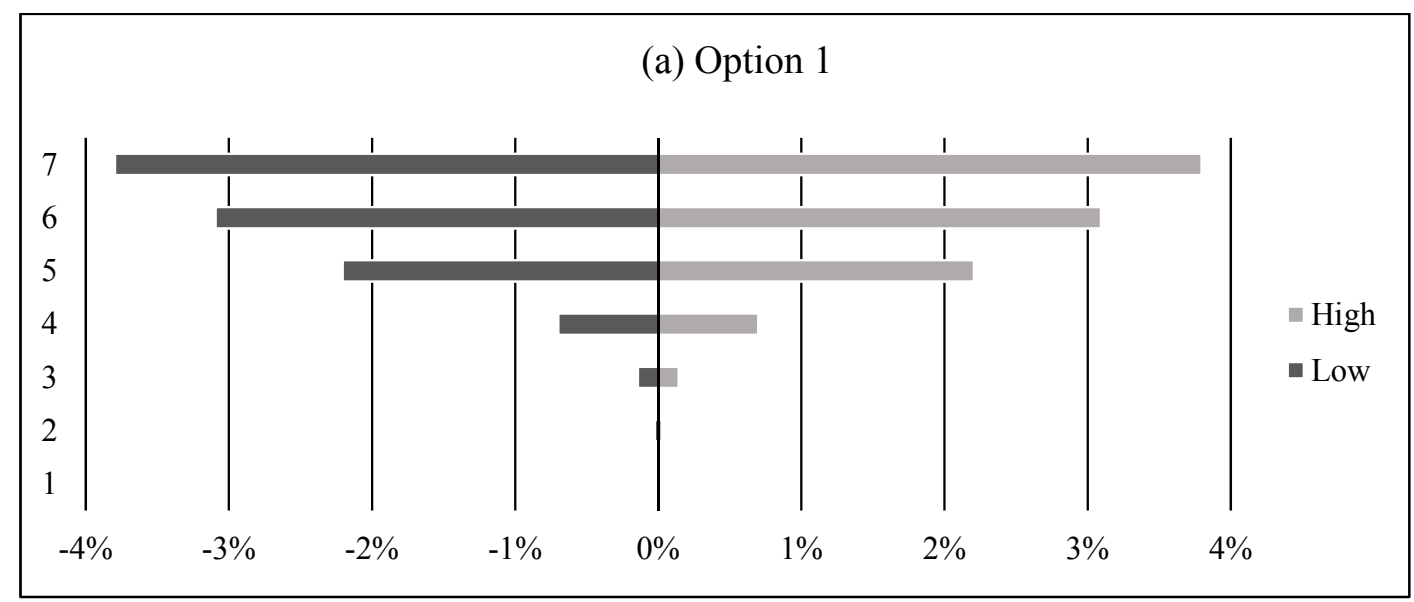

(1) Herbicide production, (2) Transport distances (herbicide and fumigant), (3) Transport of wastes, (4) Fuel consumed for all agricultural processes), (5) Transport of feed (tomato pomace), (6) Plastic sheeting used (production and landfilled) and (7) Fumigant production.

Fig. 7. Sensitivity analysis for Option 1 (a) Option 2 (b) and Option 3 (c) for global warming potential $\left(\mathrm{kg} \mathrm{CO}_{2}-\mathrm{e}\right)$ : processes changed $+/-10 \%$. 